\title{
Saxon and Norman Sculpture in Durham
}

\author{
by G. BaLdWIN Brown \\ Professor Emeritus of Fine Art, Edinburgh University
}

$\mathrm{W}$

HEN one phase of decorative art for reasons historical, social, or religious, passes out of existence and is succeeded by another, there generally occurs what is technically termed an 'overlap'. This is so common that it is often accepted without consideration as universal, and the expression 'Saxo-Norman overlap' is employed with reference to architecture of early twelfth century where it has validity, but also to decorative sculpture where it possesses no solid ground or meaning. Saxon stone carving is on different lines from Norman and the two do not coalesce, the Norman enriched tympanum carrying the Norman art, the freestanding carved cross the Saxon art. The above must be left for the moment as a statement which will later on receive its due explanation and support, but the subject of the present brief paper is germane to it.

It so happens that we possess datable specimens of late Saxon and early Norman sculpture in the shape of carved heads belonging to Saxon crosses that stood on the future site of the Norman Chapter House of Durham Cathedral and may be dated early in the eleventh century, and Norman enriched capitals of columns in the early Castle Chapel that can be placed in date before the year r roo. This early Norman chapel, which is of course quite apart from the Cathedral, is involved in the extensive works of preservation going on in the Palace-Castle, and the Clerk of Works in charge is Mr C. Singe, who unites with a genuine scholarly interest in old work expert skill with the camera. At the suggestion of the writer he has taken a series of views of the capitals of the Chapel columns, among the first examples of Norman decorative sculpture in England. These photographs are reproduced here, not on account of any beauty to which they may lay claim, but as interesting historical documents. They are accompanied by a few explanatory notes. As a piece of Saxon work 


\section{SAXON AND NORMAN SCULPTURE}

for comparison there has been added a view of the best preserved example of the Chapter House cross-heads, which are more or less contemporary in date but in quite a different style of work. With the Normans the architectonic sense and the spirit of system are supreme, while the Saxon fancy, as evidenced on the early Sceatta coins, is far more inventive and lively.

There are in the Chapel six columns supporting the vaulted roof, in two rows of three in each, a north and a south row. The southwest column is numbered $\mathrm{x}$, the middle one in the south row is 2 , and the southeast column on the altar steps is 3 . In the other row number 4 is the northwest column and numbers 5 and 6 follow towards the east. Each of the six capitals would provide four views, but the five specimens out of the possible twenty-four are quite sufficient to give an idea of the design and execution of the work which is carried out in stone. The photographs are arranged in numerical order according to the scheme just given.

Plate I, NW corner of number 2. Two quadrupeds, one on the west the other on the north face of the cap, have their heads joined together at the corner and take the place of a volute. Most of the surface of the cap is covered with irregular 'chip-carving' in stone, showing the beginning of what became systematized into the 'star' patterns, etc., of the twelfth century.

Plate 2, SE corner of no. 3. At each corner there is a grotesque human figure with the large head boldly and skilfully modelled, and it is characteristically Norman to note that the head is so treated as to correspond in general form to the carved volutes of the capitals as a whole. This is Norman 'system ' in operation. On all the caps the middle spaces between the volutes or other corner ornaments are occupied with some ornamental motives, most generally by very stiff and formal conventional foliage. Under these sprays we find often, as here on no. 3 , a human mask.

Plate 3 , sw corner of no. 6. This cap is more severely architectural than most of the others. There is at each corner a volute, and this, with the other similar corner volutes, gives us the characteristic difference between Norman and Saxon work. No Saxon carver could have given his architectural member so clear and firmly modelled a shape, just as no Norman could give such liveliness and grace to 


\section{ANTIQUI'TY}

bits of foliage or to animals as came naturally to the Saxon. Here on no. 6 the middle space on the south has, above, a conventional spray, and, below, a flat and ugly human mask. A similar head on the western face is far better. It has an open mouth with tongue showing and a beard. There are two small horns on the forehead and ears pricked up above.

Plate 4, NE corner of no. 5. Here are better and less Saxonic volutes than we find anywhere else. The tameness and want of grace in the foliage sprays on the middle spaces will be apparent.

Plate 5, Nw corner of no. 4. The western face of this cap is occupied with an ambitiously designed quadruped who stands facing south. The body is treated with incised diagonals, evidently suggested by the stones set lozenge-fashion on so many pieces of Norman walling. The head is furnished with stag's horns, and under its snout there appears to be crouching a human figure facing south with a huddled up creature south of it. House.

Plate 6, Saxon cross-head from the foundations of the Chapter

This is one of four cross-heads of the latest Saxon period, pretty surely within half-a-century of the early Norman caps, and shows, not ruder, but more fanciful and irregular, work. In the central round the Agnus Dei, with right forefoot on a sacred book, and very fair proportions, possesses life and animation. This central figure is surrounded by the Evangelists - Luke and Mark on the side-arms in the form of human bodies with the symbolic animals' heads, and with lions' feet under Mark (sinister side). Matthew is represented by the Angel above, while for St. John we must look to the back of the topmost arm (not shown here) where is a fairly successful eagle. What the carver meant by all his quaint details it is not possible to say, but the contrast that the work presents to that of the Norman designer is most significant of the difference between the two arts. 
PLATE I

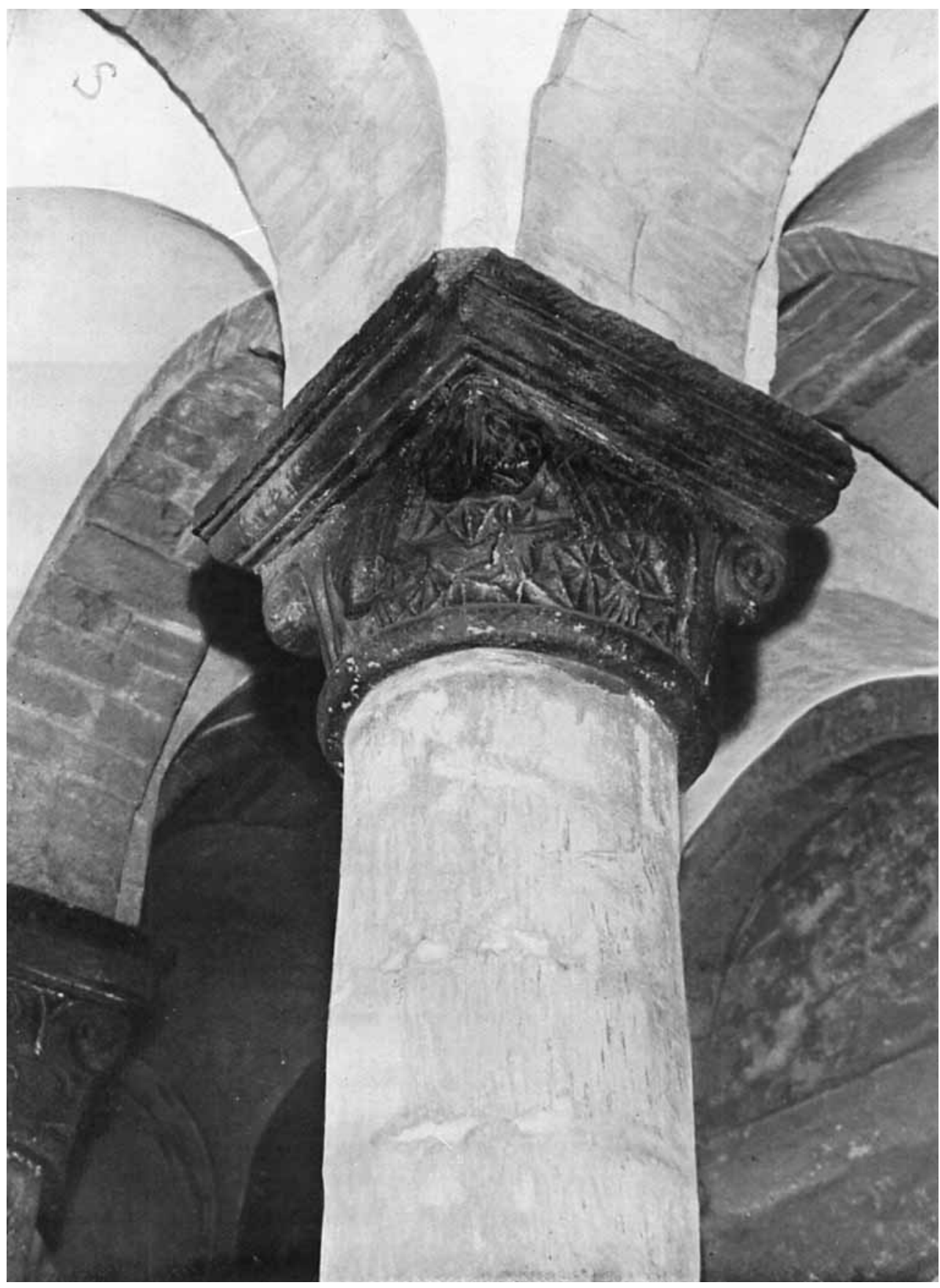

SCULPTURE IN THE CASTLE CHAPEL, DURHAM

Northwest corner of cap of column 2

$P h$. (pls. I-v) Mr C. Singe

facing $p .440$ 


\section{PLATE II}

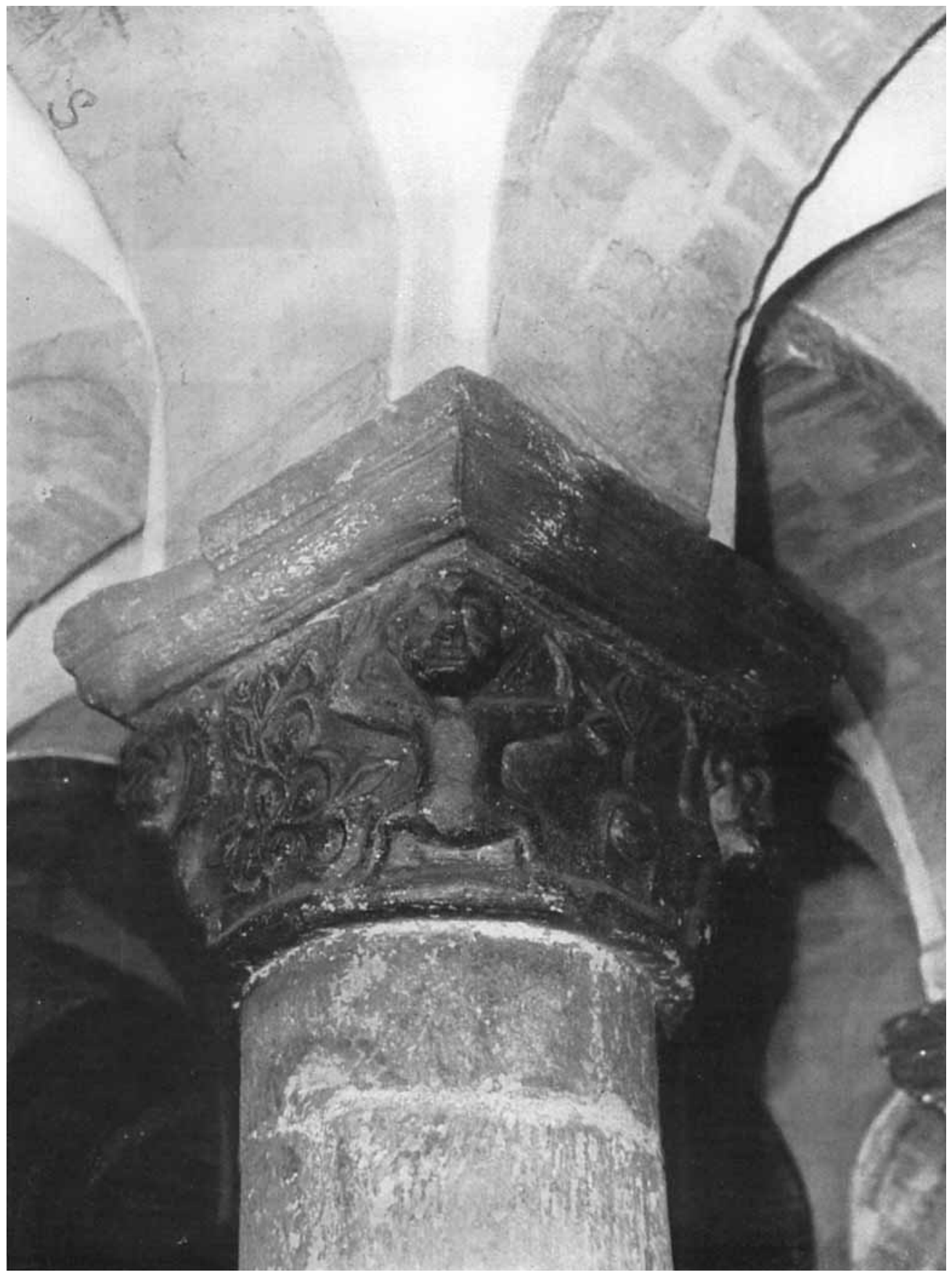

SCULPTURE IN THE CASTLE CHAPEL, DURHAM

Southeast corner of cap of column 3 


\section{PLATE III}

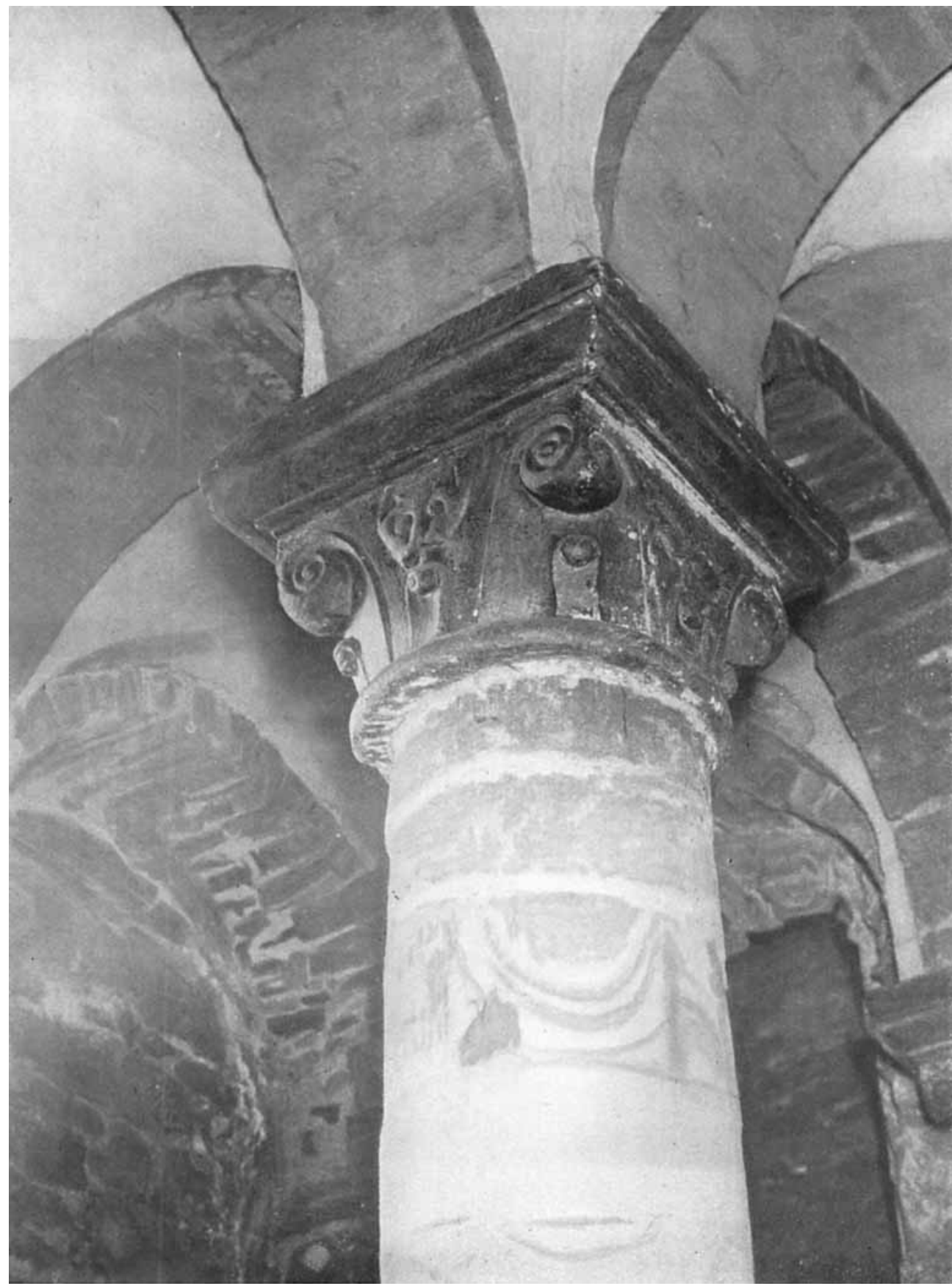

SCULPTURE IN THE CASTLE CHAPEL, DURHAM

Southwest corner of cap of column 6 


\section{PLATE IV}

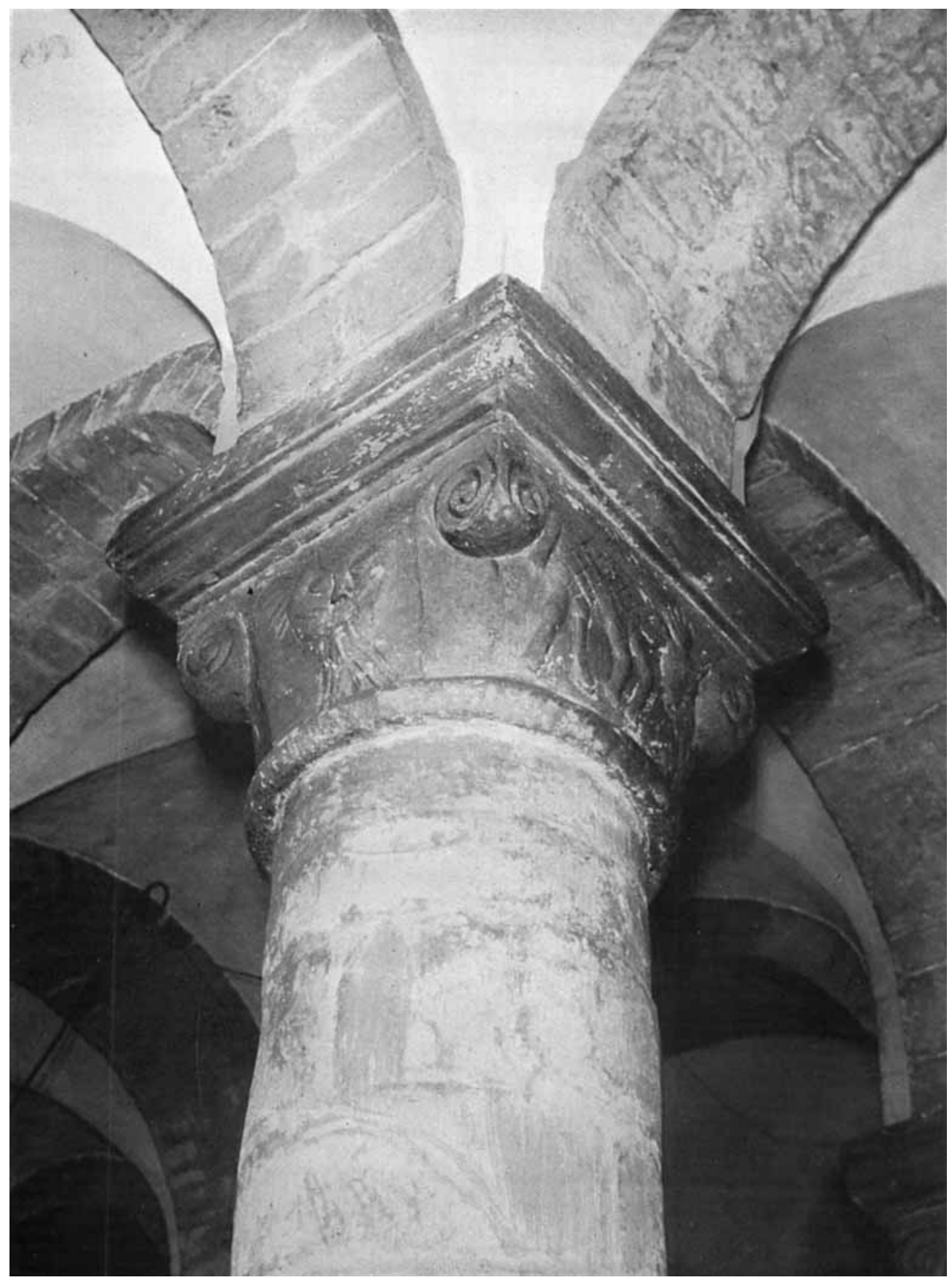

SCULPTURE IN THE CASTLE CHAPEL, DURHAM

Northwest corner of cap of colunn 5 


\section{PLATE V}

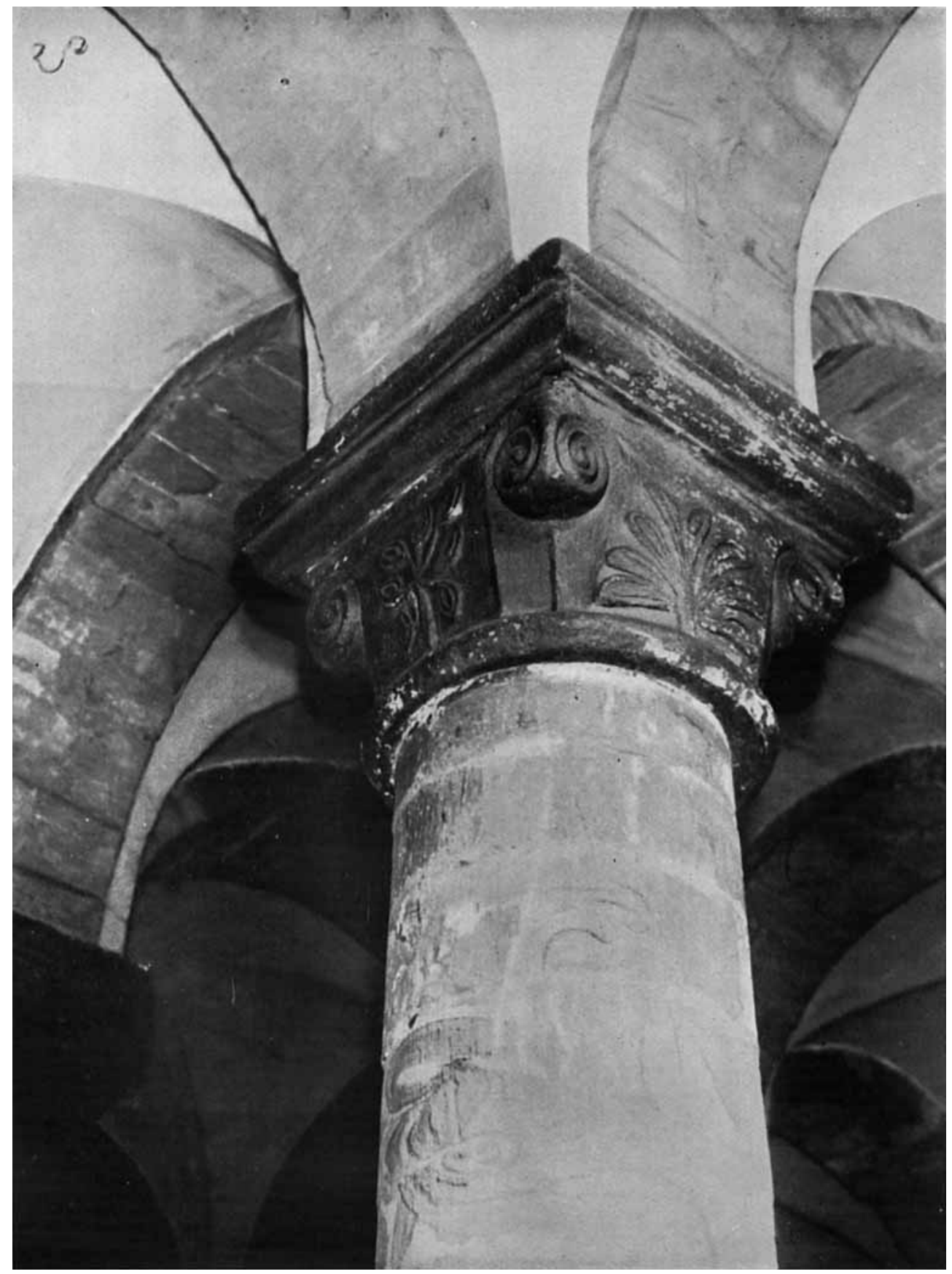

SCULPTURE IN THE CASTLE CHAPEL, DURHAM

Northeast corner of cap of column 4 
PLATE VI

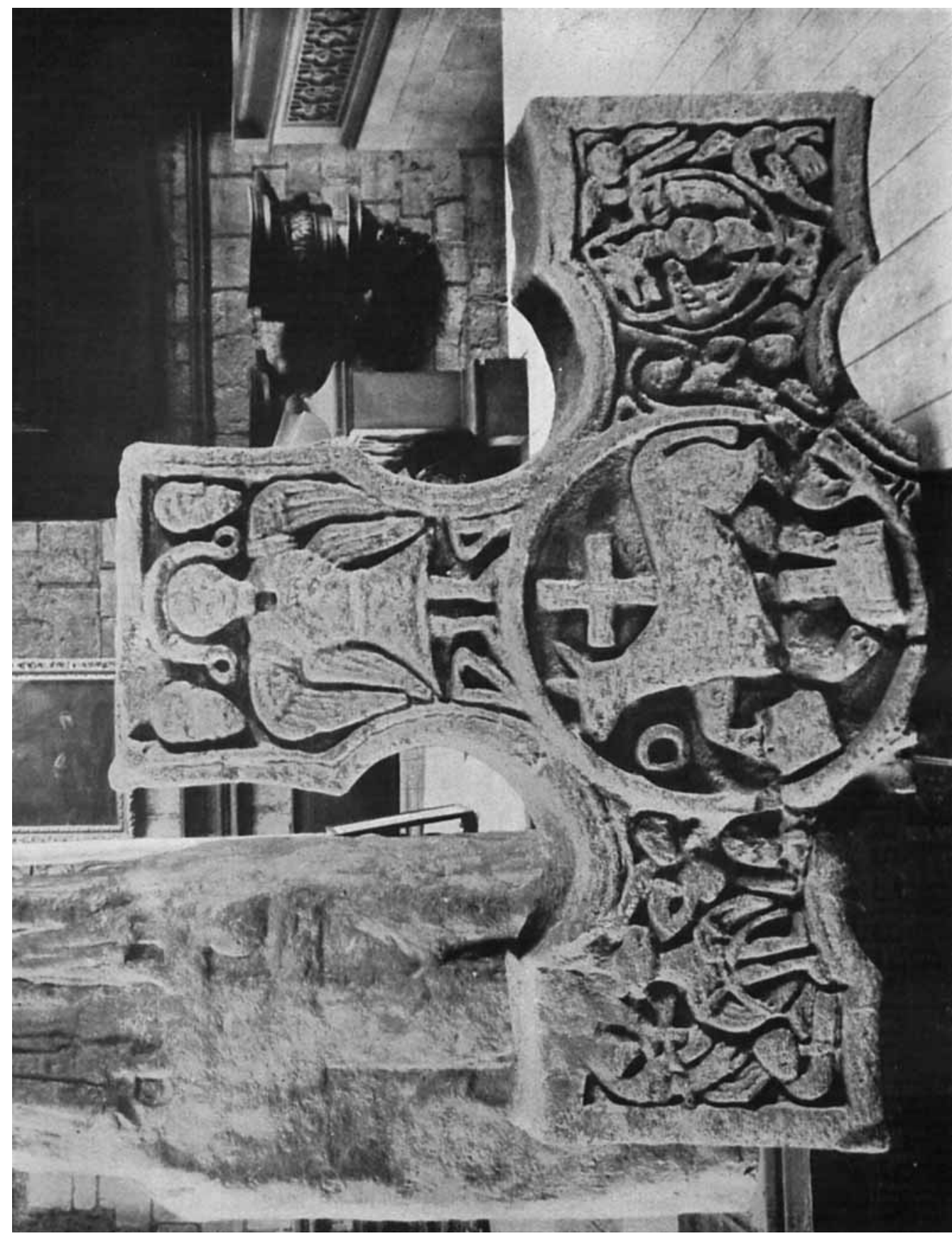

要 